\title{
Studying of the combined salts effect on the engineering properties of clayey soil
}

\author{
Anwar Al-Obaidi ${ }^{1, *}$, Alaa Ihssan ${ }^{1}$, and Hamed Allawi ${ }^{1}$ \\ ${ }^{1}$ Building research directorate, Ministry of housing and construction, Baghdad, Iraq
}

\begin{abstract}
In recent years, a number of studies had been performed to investigate the effect of pore water chemistry on the strength and compressibility characteristics of soil. Although the effect of chloride and sulfates salts separately in pore fluids on the geotechnical properties of soil seems to be well understood, but the influence of combined effect of sulfates and chlorides in pore water on the behavior of soil is still unclear mostly due to the limited numbers of studies as well as the complexity of processes that may occur in soil (with the presence of salts) in pore water-soil interaction. Southern regions of Iraq, especially Basra suffers from low water levels in the summer season in addition to the lack of rain water, which causes a significant increase of salt in the Shatt al Arab. Water salinity continues to increase with time. To investigate the combined impacts of water salinity on the behavior of clayey soils, the basic characteristics of the soil brought from Al-Nahrawan site was studied. Chemical methods were done with three types of water (distilled, water of highly saline as Shatt Al-Arab water and water of Tarmiya as moderate saline water). The effect of water salinity on the geotechnical properties of fine grain soil was investigated. Different laboratory tests such as Atterberg limits, standard compaction, consolidation and shear strength of soil .Results showed that the presence of perceptible amounts of dissolved salts in water can lead to changes in the engineering properties of the soil.
\end{abstract}

\section{Introduction}

Soil is a mixture of several compounds such as soil solid, air voids and pore water. Water is well known to be strongly attracted to the soil surface. Mitchell (1993) [6] in their soil investigations stated that fabric and bonding both characterise the structure of soils. Micro structural consideration considers that the fabric is mainly referred to soils solid particle arrangement and its flocculation process, yet bonding is dominated by the inter particle forces. Pore properties of the fluid have a direct impact on both the fabric and the bonding mechanism. This is related to the water-soils interaction of clays (Mitchell and Soga, 2005[7]). The term 'salinity' represents the soluble salts total concentration in the soil. Those salinity salts come in different forms including calcium , magnesium, chlorides, sulphates or even carbonates of sodium, Pore water salinity influence on the behavior of solid soil particles as a result to the chemical interaction that may occur between the soil particles and the ions in the pore water. This is clearly observed in fine-grained soils. Studies have proved that many material macroscopic characteristics (e.g., shear stiffness, compressibility, etc.) are affected by pore water salinity concentrations. Yet salinity influence on the geotechnical properties of soil is still yet to be further investigated. The current study looks into the relationships bonding between salt content that fills the gap and the geotechnical properties of fine-grained soils.

\subsection{Clay water interaction}

Clays are known to be hydrophobic colloid. Their behaviors is generally dominated by the surface forces. Surface forces play an important role in the formation of soil microstructure and water-soil interactions (van Olphen, 1991 [9]; Mitchell and Soga, 2005 [7] ).

Negative charged surface and adjacent charges are termed to the diffuse double layer. Ions distribution among the diffuse double layer may cause unbalanced force field near the clay surface. This can generate inter particle forces when two soil particles get closed. The double layer forces may change the movement of soil particles and impact soil behaviors.

Corresponding author: alobeydi 63@yahoo.com 


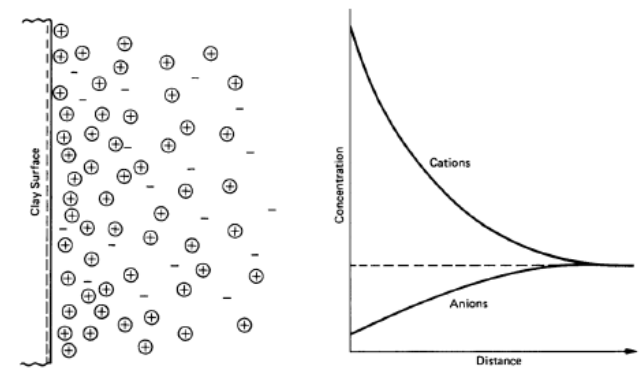

Fig. 1. Ions concentrations in the diffuse double layer phase (after Mitchell and Soga, 2005) [7]

\subsection{Effect of water salinity on soils geotechnical properties}

In recent years, a number of studies have been performed to look into the effect of the chemistry of pore water and its impacts on the geotechnical characteristics of soil. Anandhanarayanan and Murugaiyan,(2014) [3] investigated the effect of sea water and different inorganic salt solutions (as permeant liquids) on the compaction characteristics, liquid limit, free swelling, consolidation characteristics and hydraulic conductivity of different types of clay-bentonite mixtures. Sea water and salt solution increased the maximum dry density and decreased the optimum water content of mixtures .Higher cation valance leads to higher increase in the maximum dry density and higher decrease in optimum water content, by increasing the sea water and salt concentration the swelling volume and liquid limit decreases. Higher cation valance and salt concentration cause higher decrease in liquid limit by increasing the sea water and salt water concentration, the compression index decreases the hydraulic conductivity of the samples increases by adding the salt water and sea water.

The salinity of the water has been shown to effects on the geotechnical properties of fine soils used in Korchay dam core had been studied Ajalloeian, et al.,(2013) [1]. Several soil measurments as ( Atterberg limits, compaction, consolidation, direct shear and dispersion (pinhole and chemical) ) have been carried out by the use of waters of different salt concentrations ( distilled, half saline and saline waters). The charges in the geotechnical properties of the soil were neglected as there were a some percent of active clay minerals found in the soil. Results revealed the values of the Atterberg limits, compression index and swelling index decrease and consolidation coefficient and shear strength parameters increase as the amount of pore water salinity increases. When comparing those results with other tests carried out using water that has been desalinized, the effect of water salinity on consolidation under high pressures is not consideration. Dispersion tests also revealed that there was no dispersion in the soil when contacted with waters of high salinity.

Aksoy, et al.,(2008) [2] examined the sea water effects on consistency limits and compressibility properties of clayey soils of low and high plasticity.The results revealed that sea water impacts were almost negligible on the tested consistency limitsand compressibility characteristics of soils when they have liquid limits up to $110 \%$. The sea water effect is mostly noticed on the consistency limits and compressibility of Na-bentonites.

\section{Experimental works}

\subsection{Soil samples}

The following tests were done to determine the physical and engineering properties, salinity and $\mathrm{pH}$ of soil sample collected from Al-Nahrawan site.

1- Specific Gravity (ASTM D854)

2- Atterberg Limit (ASTM D 4318)

3- Grain Size Analysis (ASTM D 422)

4- Moisture Content (ASTM D 2216-90)

5- Unit Weight (ASTM D 1556-00)

6- Shear Strength (ASTM D 2166)

7- Consolidation (ASTM D 4186)

8-pH (ASTM D4972-01)

The soil samples have been collected from AlNahrawan brick factory. Figure (2) shows the distribution of the grain sizes of the soil materials of the collected samples. In this graph it is seen that the soil distribution contained of $44 \%$ silt and $56 \%$ clay. According to (liquid limit and plasticity index) and in reference to grain size distribution, the soil can be classified as lean clay (CL) using unified soil classification system. Chemical methods were done with three types of water (distilled, Shatt Al-Arab ( highly saline water) and water of Tarmia ( moderate

saline water).Concentrations of cations and anions of the waters utilized in this investigation had the specifications listed in Table (1). The cation charge showed to have played an important part in increasing double layer thickness and in decreasing interparticle attractive force. The effect of three types of water (i.e. saline, half saline and distilled water) on geotechnical properties of fine grained soil had been investigated in this research. Tests including hydrometer Atterberg limits, standard compaction, consolidation, direct shear test and unconfined compression were also performed. 


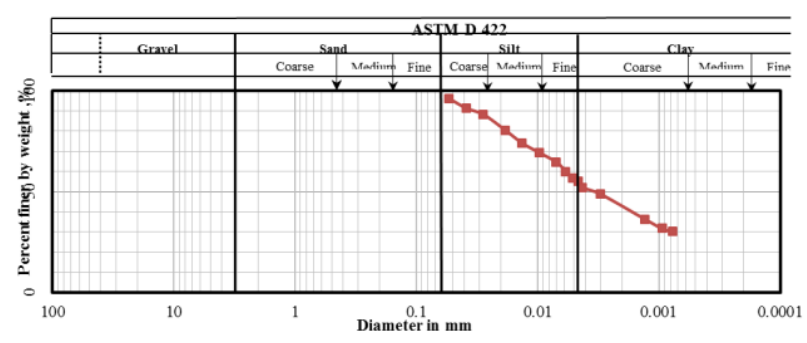

Fig. 2. Grain size distribution of Al-Nahrawan site

Table 1. Chemical analysis of Waters studied

\begin{tabular}{|c|c|c|c|c|c|c|c|}
\hline $\begin{array}{l}\text { Type } \\
\text { of } \\
\text { water }\end{array}$ & $\mathrm{pH}$ & $\mathrm{Cl}^{-1}$ & $\mathrm{SO}_{4}^{-2}$ & $\mathrm{Na}^{+1}$ & $\mathrm{~K}^{+1}$ & $\mathrm{Mg}_{2}^{+}$ & $\mathrm{Ca}^{+2}$ \\
\hline $\begin{array}{c}\text { Distille } \\
\mathrm{d}\end{array}$ & 7.2 & 0.73 & 12.1 & -- & --- & --- & --- \\
\hline $\begin{array}{c}\text { Al- } \\
\text { Tarmia }\end{array}$ & 7.6 & 6.39 & 26.5 & -- & --- & --- & --- \\
\hline $\begin{array}{l}\text { Shatt- } \\
\text { Al- } \\
\text { Arab }\end{array}$ & 8.0 & 65.3 & 45.9 & 30.9 & 5.0 & 14.7 & 28.2 \\
\hline
\end{tabular}

\section{Results and discussions}

\subsection{Effect on consistency limits}

Fig. 3. presents the results of the liquid limit (LL), plastic limit(PL) and plasticity index(PI)with different types of water.

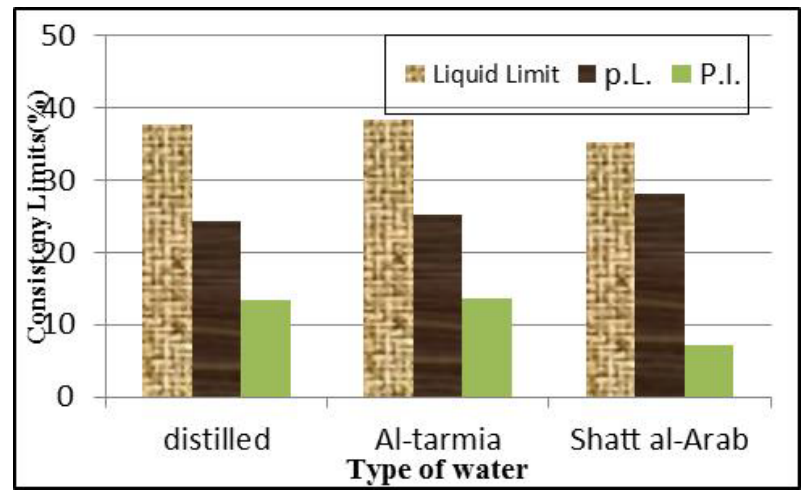

Fig. 3.Effect of Salinity of water on consistency limits

The results shows that the liquid limit of soil when mixed with distilled water is $37.6 \%$ and it does not seem to increase significantly when mixed with moderate saline water then decreased when mixed with highly saline water (shatt al-Arab).Plastic limit is increased in all types of saline water.Increasing the salt concentration, the cationvalence decreases the interparticle distances, resulting in the decrease of the liquid limit. Ajalloeian et al., (2013) [1] noticed that time of exposure has no effect on changing Atterberg limits.

\subsection{Variation of compaction characteristics with Salinity}

Fig.4. shows the results of compaction tests performed with waters of different salinity. Relaying on Ajalloeian et al., (2013) [1] results on compaction, Atterberg and exposure time showed that these are not effective factors in the results. In Fig. (4) there were no distinguished differences between these curves. Yet the results have shown that the optimum moisture content has decreased and maximum dry unit weight of the soil has increased when mixing with saline water and the results is more pronounced when the salinity is moderate.
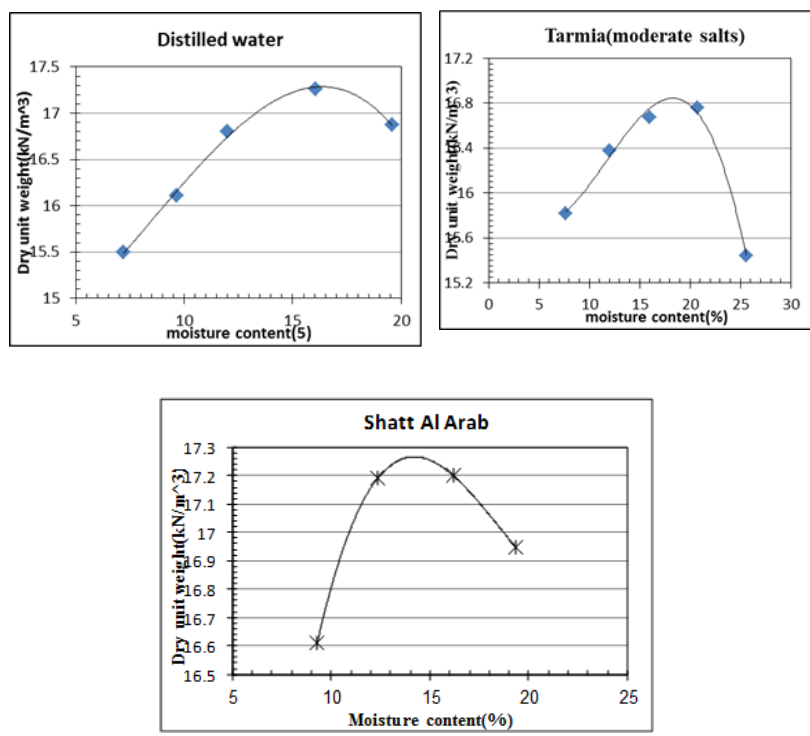

Fig. 4. Effect of salinity of water on compaction characteristics

\subsection{Effect of salinity on consolidation characteristics of soil}

Fig.5. shows results of the one dimension consolidation test of three times performance with all types of water as well as compacted soil. Logarithmic vertical stress relationship against void ratios was used to determine the Compression index (Cc) and swelling index (Cs). Average values of compression index $(\mathrm{Cc})$ of distilled water, half saline water and saline water were 0.159 , 0.1067 and 0.095 respectively as seen in Fig.6. The results come in agreement with other studies. Compression index value reduction can be related to the reduction of double layer thickness and increasing of attractive force between particles as pore fluid concentration increases. 

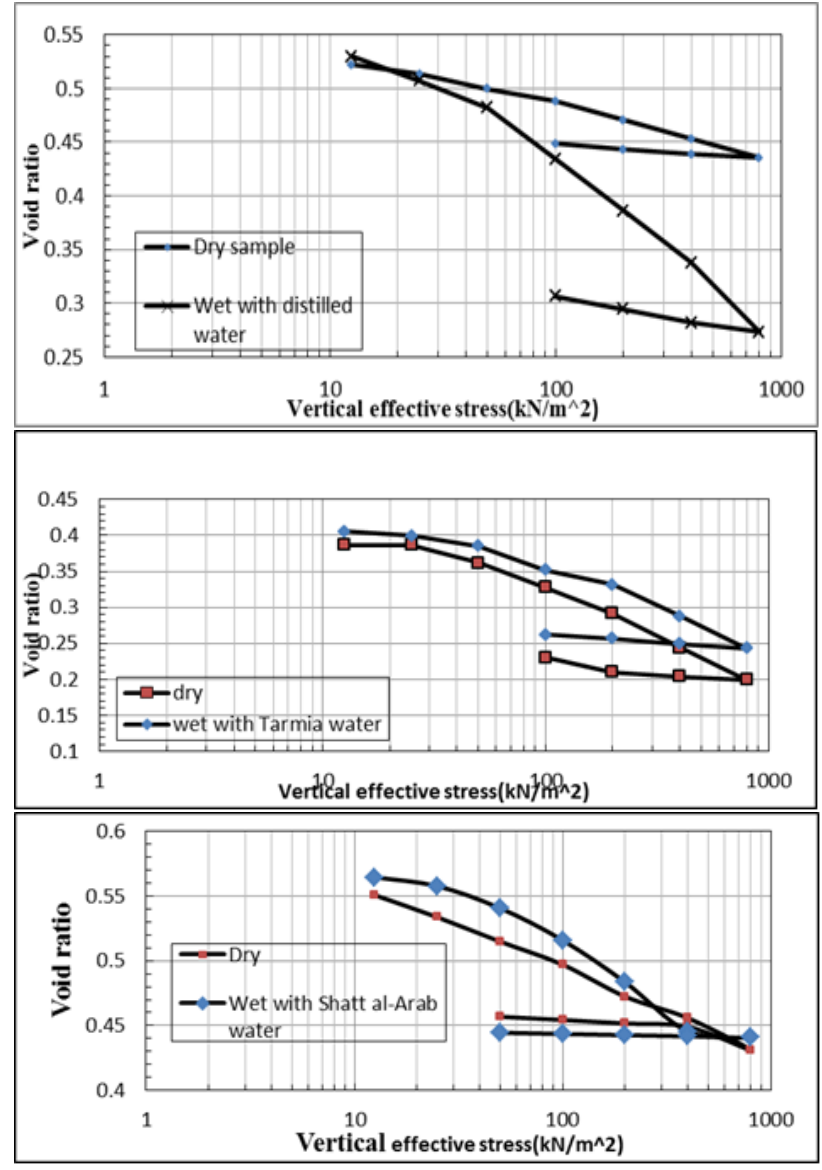

Fig.5. Effect of salinity of water on consolidation

It can be concluded that high concentration of the salt concentrations in the water has increased the attraction forces present between the particles. Moreover, this established a better bonding among the particles. Consequently flocculation structure has formed in the soil. Also salt crystals may sediment in the pores of soil and play role of cement. In this condition, subsidence of soil and compression index will be lower.

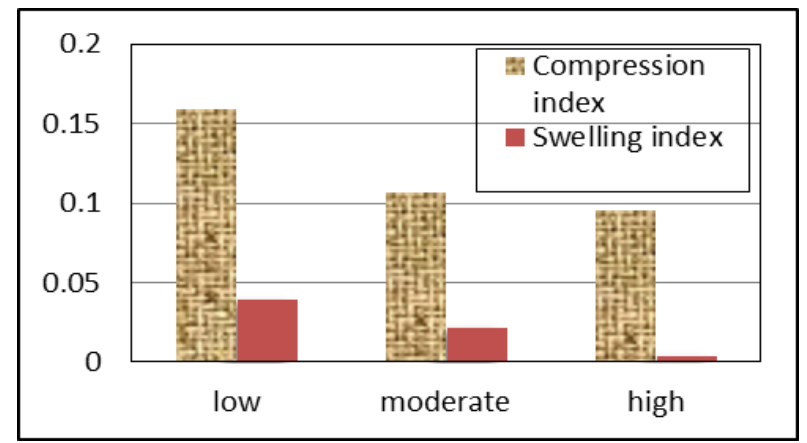

Fig.6. Compression index and swelling index versus salinity of water

It was observed that the swell index (Cs) has also decreased in respect to water salinity increment. The average values of the swell index (Cs) with distilled water, half saline water and saline water have been found to be $0.039,0.0215$ and 0.0033 respectively. The changes can be related to the differences of the osmotic pressure. High concentration of the half saline and saline water, osmotic pressure difference between water within layers of clay and water in the pores of soil has been observed to be lower in comparison with the distilled water. So after unloading, less water enters to the space between layers of clay to balance osmotic pressure. Hence Cs has decreased as salinity of water increases. In Fig.7. illustrates the effect of salinity of water on modulus of volume compressibility (mv) in the stress $200 \mathrm{kN} / \mathrm{m}^{2}$.It is seen that the modulus of volume compressibility decreases with increasing salinity of water. This change is due to decrease in double layer thickness as concentration of water increases.

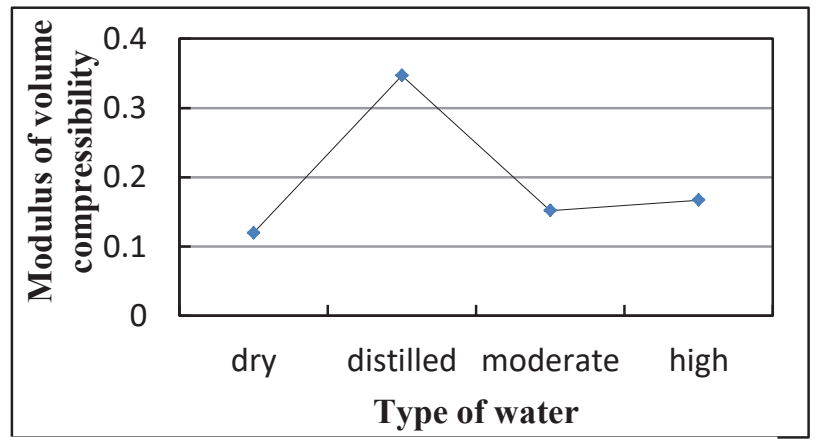

Fig.7. Modulus of volume compressibility Vs . Water salinity

\subsection{Effect of salinity on undrained shear strength of the soil}

\subsubsection{Unconfined compressive tests}

The effect of water salinity on the unconfined compressive strength for the Al-Nahrawan soil is presented in Fig.8. The ultimate strength of samples decreased significantly with increasing water salinity as shown. Results also showed that mixing saline water with soils decreased its undrained compressive strength characteristics as shown in Fig.9. In general, the soils displayed low unconfined compressive strength with increasing salinity than with distilled water. This may be attributed such a strength decrease to the fact that the salt forms brine with water; this brine forms a film around each particle, which decreases the strength of the particles since brine film is weak in surface tension than ordinary moisture, thus it decreases the cohesion of the particles. 


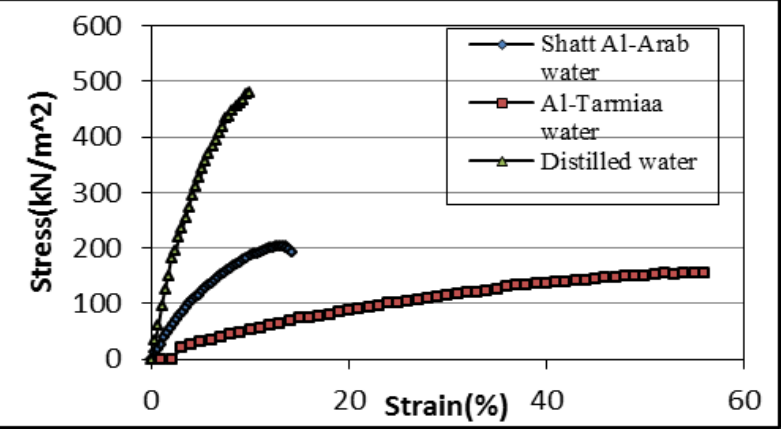

Fig.8. Effect of salinity of water on the unconfined compressive strength of Al-Nahrawan soil

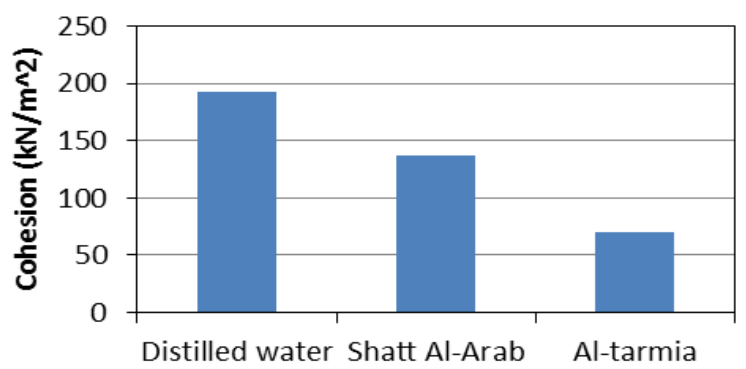

Fig. 9. Effect of salinity of water on undrained shear strength $(\mathrm{Cu})$

\subsubsection{Direct shear test}

The plot of stress-strain curve obtained after conducting the shear tests is shown in Fig. 9. for as compacted specimens with different water salinity and Fig. 10. for specimens repaired as compacted and then immersed with different water salinity. The fit line was drawn starting from the undrained shear resistance versus percent salt content for direct shear tests to study the effect of different salinity solution on undrained shear strength of the soil.

In general (both as compacted and saturated) the cohesion is decreased with increasing salinity. These results are coinciding with the results obtained from unconfined compression tests.The surfaces of soil particles hold negative or positive charges due to isomorphous substitution process. These surface charges lead to electronic interparticle forces and affect the behavior of soils. The charged surfaces of soil particle have interaction with the dissolved ions in the pore water and influence soil behaviour. Generally, most of the soil particle surfaces hold negative charges caused by isomorphous substitution. Cations are attracted by the negative surface charges and held on the surface of soil particle. Due to the absorbed cations, the electronic forces between soil particles are influenced. In this way, the ion concentration (the salt content) of pore water affects the behavior of soil particles and the properties of soils.

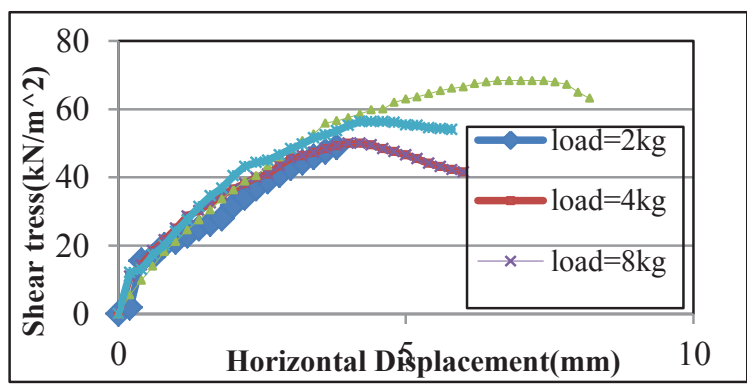

(a)Distilled water

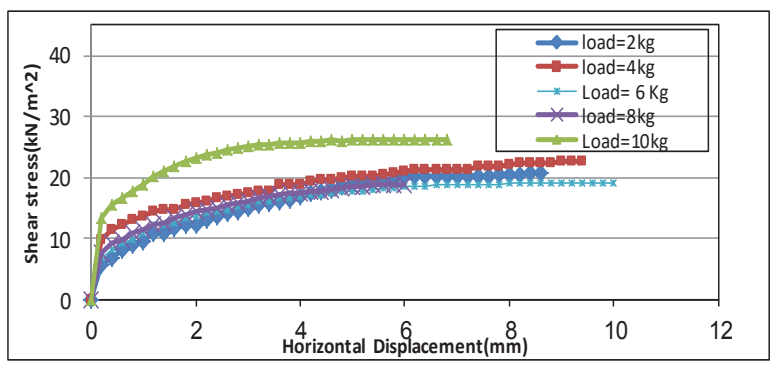

(b)Al-Tarmia water

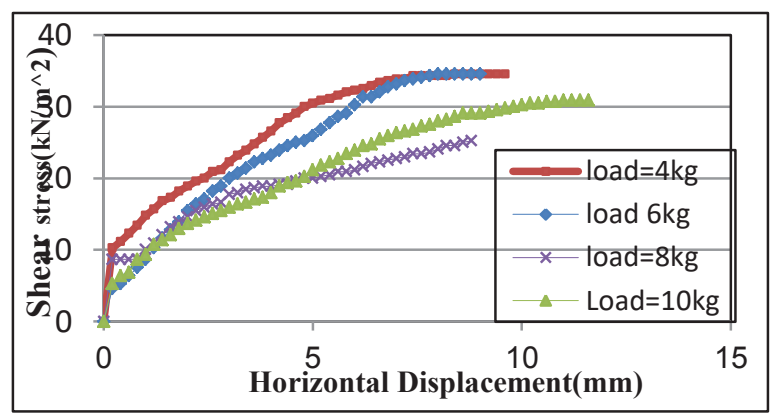

(c) Shatt Al-Arab water

Fig. 10. Effect of salinity of water on stress strain curve for as compacted specimens 


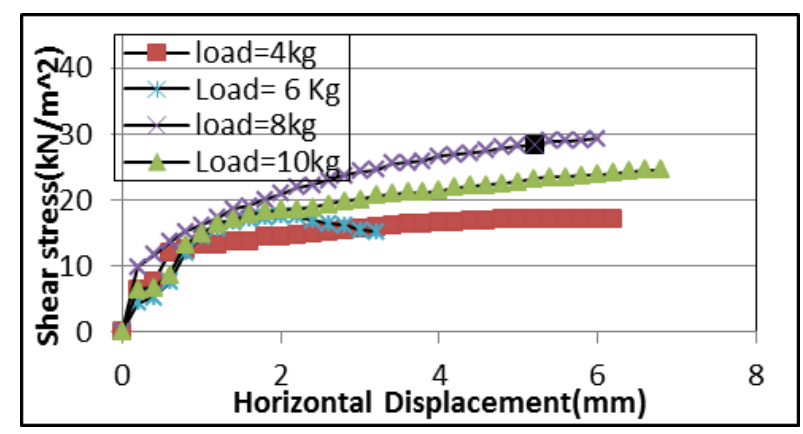

(a)Immersed with distilled water

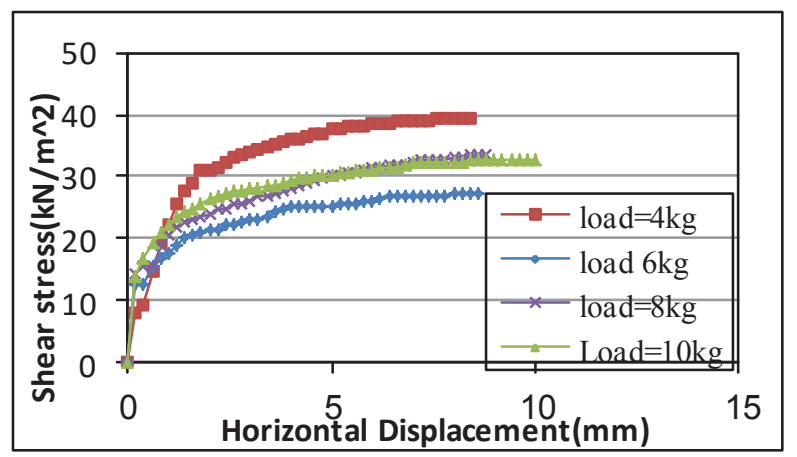

b)Immersed with Al-Tarmia water

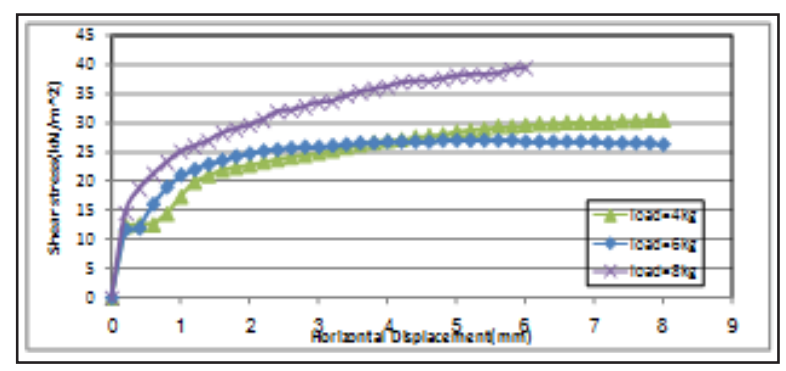

(c) Immersed with Shatt-Al-Arab water

Fig. 11. Effect of salinity of water (using in immersed specimens) on stress-strain curve for as compacted specimens

\section{Conclusions}

Based on the experimental results, the following conclusions can be drawn:

1. Salt solution increment can decreases the undrained shear resistance of compacted soil due to the decreased in attractive forces as compared with distilled water.

2. A comparison between direct shear and unconfined compression tests, results showed that as the salinity of water increases, the cohesion decreases and these parameters obtained by unconfined tests may give higher value than direct shear.
3. The test results demonstrated that the salinity has a pronounced effect on compressibility. The compression index and sweelling index decreased with increasing salt concentration

4. The modulus of volume compressibility decreases with increasing salinity of water.

5. Optimum moisture content showed to decrease and maximum dry unit weight of soil showed to increase when mixing with saline water .

6. Liquid limit as well as plastic limit decreases with increasing salinity.

7. Finally, from above results care must be taken when using saline water instead of distilled water or tap water or when the soil is exposed to saline water since the salinity weaken the soil.

\section{References}

1. R. Ajalloeian, H. Mansouri, and A.H.deghpour, EJGE, 18 (2013).

2. Y.Y.Aksoy, A.Kay, and A.H. Oren, Eng. Geology 1 02, P.P. 54-61(2008).

3. G. Anandhanarayanan, V. Murugaiyan, IJERT, 3 Issue 3, March (2014).

4. ASTM, Annual Book of the ASTM Standards, 0408(2006).

5. D.Kolymbas, \& E.Bauep, GTJ, 6(2), P.P. 263270(1993).

6. J.Mitchell, Fundamentals of soil behavior, NY: Wiley (1993).

7. J.Mitchell, \& K.Soga, Fundamentals of soil behavior. $3^{\text {rd }}$ edition, New York (2005).

8. R. Ajalloeian, H. Mansouri, and A. Sadeghpour EJGE, 18, P.P.1419-1434 (2013).

9. V. Olphen, TGSC, An introduction to clay colloid chemistry, Reprint version, New York, John Wiley and Sons, (1991). 